\title{
Chronotype Modulates Sleep Duration, Sleep Quality, and Social Jet Lag in Shift-Workers
}

\author{
Myriam Juda, ${ }^{*, 1}$ Céline Vetter, ${ }^{*}$ and Till Roenneberg, \\ *Institute of Medical Psychology, Centre of Chronobiology, Ludwig Maximilian University of Munich, \\ Munich, Germany
}

\begin{abstract}
This study explores chronotype-dependent tolerance to the demands of working morning, evening, and night shifts in terms of social jet lag, sleep duration, and sleep disturbance. A total of 238 shift-workers were chronotyped with the Munich ChronoType Questionnaire for shift-workers (MCTQ ${ }^{\text {Shift }}$ ), which collects information about shift-dependent sleep duration and sleep timing. Additionally, 94 shift-workers also completed those items of the Sleep Questionnaire from the Standard Shift-Work Index (SSI) that assess sleep disturbances. Although all participants worked morning, evening, and night shifts, subsamples differed in rotation direction and speed. Sleep duration, social jet lag, and sleep disturbance were all significantly modulated by the interaction of chronotype and shift (mixed-model ANOVAs). Earlier chronotypes showed shortened sleep duration during night shifts, high social jet lag, as well as higher levels of sleep disturbance. A similar pattern was observed for later chronotypes during early shifts. Age itself only influenced sleep duration and quality per se, without showing interactions with shifts. We found that workers slept longer in fast, rotating shift schedules. Since chronotype changes with age, investigations on sleep behavior and circadian misalignment in shiftworkers have to consider chronotype to fully understand interindividual and intraindividual variability, especially in view of the current demographic changes. Given the impact of sleep on health, our results stress the importance of chronotype both in understanding the effects of shift-work on sleep and in devising solutions to reduce shift-work-related health problems.
\end{abstract}

Keywords chronotype, MCTQ ${ }^{\text {Shift }}$, shift-work, circadian misalignment, social jet lag, sleep duration, sleep quality, age

For at least 2 decades, research has shown that shift-work causes sleep disturbances and fatigue (Carskadon and Dement, 1981, 1987; Czeisler et al., 1986; Czeisler et al., 1990; Härmä et al., 1998). Shiftworkers commonly experience difficulties in initiating, maintaining, and consolidating sleep (Åkerstedt, 1983, 2003), and these disturbances are believed to cause excessive fatigue (e.g., Åkerstedt, 1998). Up to
$90 \%$ of shift-workers report regular sleepiness at the workplace, and up to $20 \%$ report involuntary sleep bouts at work (Akerstedt, 1995). These results are alarming in view of work-related accidents and injuries (Berger and Hobbs, 2006; de Pinho et al., 2006; Folkard and Lombardi, 2004; Folkard and Tucker, 2003; Häkkänen and Summala, 2000; Pandi-Perumal et al., 2006; Roth and Ancoli-Israel, 1999). Circadian

1. Present address: Department of Psychology, University of British Columbia, Vancouver, BC, Canada.

2. To whom all correspondence should be addressed: Till Roenneberg, Institute of Medical Psychology, Centre of Chronobiology, Ludwig Maximilian University of Munich, Goethestr. 31, D-80336 Munich, Germany; e-mail: roenneberg@lmu.de.

JOURNAL OF BIOLOGICAL RHYTHMS, Vol. 28 No. 2, April 2013 141-151

DOI: $10.1177 / 0748730412475042$

(c) 2013 The Author(s) 
misalignment is one of the proposed explanations for shift-work-related sleep problems (e.g., Härmä, 1993). The discrepancy between circadian and social (work-enforced) sleep times (social jet lag; Wittmann et al., 2006) is extreme in shift-workers since their body clocks appear to remain synchronized with the natural light/dark cycle rather than with the substantial and regular displacements in activity and sleep (Åkerstedt, 2003; Folkard, 2008; Folkard et al., 1985; Juda et al., 2013).

Circadian clocks entrain differently in every individual to the light/dark (chronotypes), so that the differences between the extreme early and late chronotypes can span across 12 hours (Roenneberg et al., 2003; Roenneberg et al., 2007a). Mid-sleep on free days (corrected for "oversleep," $\mathrm{MSF}_{\mathrm{sc}}$ ) as assessed by the Munich ChronoType Questionnaire (MCTQ; Roenneberg et al., 2003) has proven to be an excellent predictor of chronotype, showing high test-retest reli-

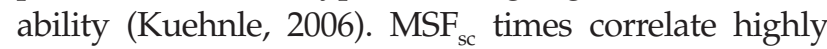
with those obtained by daily sleep logs and activity recordings (Kantermann et al., 2007; Kuehnle, 2006) as well as with biochemical markers (e.g., melatonin; Martin and Eastman, 2002; Burgess et al., 2003; Burgess and Eastman, 2005). Several questionnaires assessing diurnal preference, mostly relying on scores rather than times, have been devised since the 1970s (e.g., Composite Scale of Morningness [Greenwood, 1992],Morningness/ Eveningness Questionnaire [MEQ] [Horne and Østberg, 1976], Diurnal Type Scale [Torsvall and Åkerstedt, 1980]). We recently developed a version of the MCTQ (Roenneberg et al., 2003) for chronotyping shift-

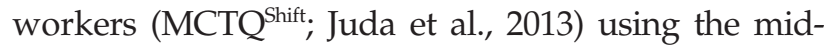
sleep time on free days following evening shifts (corrected for oversleep, $\mathrm{MSF}^{\mathrm{E}}{ }_{\text {sc }}$; for details, see Materials and Methods and Juda et al., 2013). Analysis of the $\mathrm{MCTQ}^{\text {Shift }}$ variables gives rise to more than 20 variables related to sleep/wake behavior for each shift (separately for work and free days). Furthermore, itexpresses chronotype as time (as opposed to a score), which makes evaluations with other time variables (e.g., work schedules) more amenable. Unlike all other chronotype questionnaires, it provides correction algorithms for the effect of geographical locations (e.g., latitude; Roenneberg et al., 2012; Roenneberg et al., 2007b), which are necessary when comparing samples from different sites.

Previous research has shown that interindividual variation in circadian preference explains variance in sleep duration and quality in workers, who rotate through different shift schedules. Åkerstedt and Torsvall (1981) examined day workers as well as workers employed in 2- and 3-shift models. They showed that at least $20 \%$ of the variance in morning-, evening-, and night-shift sleep duration was explained by "diurnal preference" (assessed by the Diurnal Type Scale; Torsvall and Åkerstedt, 1980). Sleep complaints were hardly influenced by diurnal preferences in this study, except for a small effect on night shifts. Sleep quality was only affected during night shifts, suggesting sleep complaints in shiftwork mainly occur when they sleep during the day. The authors concluded that age and circadian rhythmicity were 2 major factors for sleep duration and quality and reported that age influenced sleep duration in a shift-specific manner, corroborating that the correlation between diurnal type and age (the older, the earlier) drives the effect of diurnal type rather than representing a factor on its own. Seo et al. (2000) came to similar conclusions: their study included more than 500 participants working in different shift schedules, who filled out the MEQ (Horne and Østberg, 1976) and indicated their sleep habits. Yet, age was not used as a covariate in their analyses of variance examining the impact of diurnal type on sleep duration and timing, and their population contained only $4 \%$ "evening types."

Folkard and Barton (1993) report that sleep duration after evening shifts is almost 8.5 hours, while after night shifts, it is only aproximately 6.0 hours, and before morning shifts, it is about 6.5 hours. Although morningness significanlty predicted sleep onset before morning shifts, it showed a better association with sleep onset on free days. When controlled for this variable, morningness had a negligable predictive power on sleep onset before morning shifts $(<1 \%)$. Folkard and Barton (1993) proposed that the association between free-day sleep times and those on morning shifts reflects the "forbidden zone of sleep" regulated by the circadian clock. Notably, sleep onset and mid-sleep on free days correlate highly, and the latter represents the basis for assessing chronotype with the MCTQ and the MCTQ ${ }^{\text {shift }}$.

In view of these findings and the reported influence of chronotype upon sleep behavior in day workers (e.g., Roenneberg et al., 2012), we used the $\mathrm{MCTQ}^{\text {Shift }}$ to explore the interactions between chronotype, sleep duration/quality, and shift (morning, evening, and night). First, we aimed at replicating previous results on sleep duration and quality. Second, we explored in detail how they are affected by age and chronotype. Third, we present, for the first time, the effects of shift and chronotype on social jet lag, an important MCTQ variable that quantifies how much individuals live against their biological clocks. Social jet lag may be a useful variable when 
assessing shift-work exposure within and across shift schedules.

Here, we hypothesize that early types sleep longer and better and experience less social jet lag on morning shifts than later chronotypes. Vice versa, later chronotypes sleep longer and better and have less social jet lag on night shifts. Furthermore, we examined the interactions between chronotype, age, and shiftspecific sleep behavior, expecting differential effects by shift but not by chronotype per se. Given that chronotype even varies within age groups, we expect chronotype to have a significant impact on shiftspecific sleep and wake behavior over and above the influence of age.

\section{MATERIALS AND METHODS}

\section{Participants}

A total of 371 shift-workers participated in this multifactorial study. Chronotyping with the MCTQ and $\mathrm{MCTQ}^{\text {shift }}$ requires individuals to wake up on free days by themselves (e.g., not by an alarm clock or other disturbances). After exclusion of individuals who woke up involuntarily on free days following evening shifts, the study population consisted of 238 workers rotating in a 3-shift system (transition times: $0600 \mathrm{~h}, 0200 \mathrm{~h}$, and $2200 \mathrm{~h}$ ). This main sample consisted of 83 women and 155 men (mean age, $38.8 \pm 9.6$ years), with a mean chronotype of $4.26 \pm 1.38$ (range, 1.17-8.79; assessed by $\mathrm{MSF}^{\mathrm{E}}{ }_{\text {sc }}$; see Data Analyses section and Juda et al., 2013). Note that this distribution of chronotypes is similar to the one observed in day workers and other shift-work samples with regards to its mean, range, and variance (Roenneberg et al., 2007a; Juda et al., 2013).

All participants worked full time in rotating shifts (143 and 95 rotating forward and backward, respectively). Most shift schedules were slow rotations (i.e., weekly changes or less frequent); 32 participants worked in fast rotations (i.e., $\geq 1$ shift changes per week). Please see Table 1 for an overview of demographic data of the distinct samples.

Sleep disturbance (see Materials and Methods) was assessed in a subsample of 94 shift-workers (60 women and 34 men; mean age, $36.2 \pm 10.2$ years), who only worked in slow, forward rotations (one of our industry partners allowed us to assess sleep disturbance in addition to the MCTQ ${ }^{\text {Shift }}$ ). All samples were convenience samples.

\section{Procedure}

Questionnaires were distributed to the workers at their respective workplaces between March 2006 and October 2008, to be completed at work or at home. Two questionnaires (for details, see below) were filled in once at the onset of the respective studies: the MCTQ ${ }^{\text {Shift }}$ and the "sleep disturbance" section of the Sleep Questionnaire (Knauth, unpublished, German translation, based on the Standard Shift-Work Index).

\section{Materials}

The Munich ChronoType Questionnaire for ShiftWorkers (MCTQ $\left.{ }^{\text {Shift }}\right)$. The MCTQ ${ }^{\text {Shift }}$ (Juda et al., 2013) was developed to assess the sleep/wake behavior in shift-workers (based on the Munich ChronoType 
Questionnaire; Roenneberg et al., 2003). The current version has only been validated for rotating shift schedules. The MCTQ contains simple questions about sleep timing, such as bedtime, time to get ready for sleep, sleep latency, time of wake-up, and time to get up (or time in bed after wake-up), separately for work and free days. The main difference between the original MCTQ and its shift-work version is that the set of questions for work and free days are queried for each shift. The MCTQ ${ }^{\text {Shift }}$ is currently available in English and German (the latter was used in the present study).

The answers to the MCTQ ${ }^{\text {Shift }}$ questions listed above allow calculating shift-specific sleep onset, sleep end, sleep latency, time to get up, sleep duration, and mid-sleep, separately for work and free days, as well as social jet lag (for equations, see supplementary online material of Juda et al., 2013). In shift-workers, chronotype is assessed based on midsleep between 2 free days following an evening-shift block (MSFE). Sleep during and after evening shifts is least influenced by social constraints, thereby indicating that individuals may most likely sleep according to their "circadian sleep window." This suggests that $\mathrm{MSF}^{\mathrm{E}}$ is the best candidate for chronotyping shift-workers (for a detailed discussion of how to chronotype shift-workers, please see Juda et al., 2013). As in the original MCTQ, MSFE is corrected for oversleep $\left(\mathrm{MSF}_{\mathrm{sc}}^{\mathrm{E}}\right.$ ) when individuals sleep longer on free days than on workdays. Conversion algorithms have been developed for workers whose schedules lack evening shifts (Juda et al., 2013). For the purpose of the current study, we used the MCTQ ${ }^{\text {shift }}$ to assess chronotype (MSF ${ }_{s c}$ ) as well as shift-specific social jet lag and sleep duration.

Sleep Questionnaire. Sleep quality was assessed by the German translation of the Sleep Questionnaire (Knauth, unpublished) from the Standard Shift-Work Index (SSI; Barton et al., 1995). This questionnaire assesses the extent to which sleep is disturbed (e.g., "How well do you normally sleep?"). Here, we used only those questions that relate to sleep disturbance (items 2.4-2.8) and will therefore refer to "sleep disturbance" rather than to "sleep quality." Answers to these 5 items are given on a 5-point Likert scale ("almost never" to "almost always"), with a score of 5 indicating maximal sleep disturbance.

\section{Data Processing}

The following variables are calculated from the answers given in the MCTQ ${ }^{\text {Shift }}$ (Juda et al.,
2013). Superscript $x$ is a placeholder for the different shifts (M, E, N), and subscript W/F represents variables either pertaining to free days $(F)$ or workdays $(\mathrm{W}) ; n_{\text {workdays }}$ and $n_{\text {free_days }}$ represent the number of work and free days within a shift block; subscript sc stands for the "sleep-corrected" version of MSF.

Day-specific sleep duration: $S D_{W / F}^{x}=S E_{W / F}^{x}-S O_{W / F}^{x}$.

Average sleep duration in a given shift block:

$$
\varnothing S D=\frac{S D_{w}^{x} \times n_{\text {workdays }}^{x}+S D_{F}^{x} \times n_{\text {free_days }}^{x} .}{n_{\text {workdays }}^{x}+n_{\text {free_days }}^{x}} .
$$

Day-specific mid-sleep: $M S F^{X} / M S W^{X}=S O_{W / F}^{x}+\frac{S D_{W / F}^{x}}{2}$.

Oversleep on free days: over - sleep $=S D_{F}^{x}-\varnothing S D$.

$\mathrm{MSF}^{\mathrm{x}}$ corrected for oversleep:

$$
M S F_{S C}^{x}=M S F^{x}-\frac{\text { oversleep }}{2} .
$$

To chronotype shift-workers, we use the sleep-corrected MSF of the evening shift $\left(M S F_{S C}^{E}\right)$. In analogy to the computation of social jet lag (SJL) in day workers (Wittmann et al., 2006; Roenneberg et al., 2012), we used the shift-specific mid-sleep: $S J L^{x}=M S W^{X}-M S F^{X}$.

\section{Data Analyses}

First, we assessed potential differences between the study samples with Student $t$ tests for independent samples as well as the Pearson's $\chi^{2}$ test (Table 1 ). Due to missing data, sample sizes can differ between computations.

Then, we used mixed-design ANOVAs to assess the effect of chronotype on social jet lag, sleep duration, and sleep disturbance (covariates: age, rotation speed, and shift direction). Chronotype is a continuous variable (Roenneberg, 2012); however, in the first descriptive analysis, the sample was split into early $\left(\mathrm{MSF}_{\mathrm{sc}}^{\mathrm{E}}<0400 \mathrm{~h}\right.$ ), intermediate $\left(\mathrm{MSF}_{\mathrm{sc}}^{\mathrm{E}} \geq 0400 \mathrm{~h}\right.$ and $<0500 \mathrm{~h}$ ), and late types (MSF ${ }_{\mathrm{sc}} \geq 0500 \mathrm{~h}$ ). Given that the distribution of $\mathrm{MSF}_{\mathrm{sc}}^{\mathrm{E}}$ is similar to that of $\mathrm{MSF}_{\mathrm{sc}}$ in day workers (Juda et al., 2013), we used this categorization, which separates the population of day workers in approximately equal thirds (Roenneberg et al., 2007a). Finally, significant main effects of continuous variables (i.e., age and chronotype) were further 
elucidated by (partial) correlations, either for each shift in case of interactions or, when applicable, across all shifts. In case the assumption of sphericity was violated, we used the Greenhouse-Geisser correction but also report the original degrees of freedom.

\section{RESULTS}

Average values of the main MCTQ $^{\text {Shift }}$ variables (sleep onset, sleep end, sleep latency, time to get up, alarm clock usage) on work and free days and as a function of chronotype are shown in Tables 2 and 3, respectively. Use of alarm clocks (last column in Table 2) is chronotype specific. It is highest in the early shift (remarkably still showing chronotype differences) and lowest in the evening shift. Alarm clock usage is highest in late chronotypes, even after night shifts, indicating that approximately one fifth would be able to sleep even longer after night shifts. Except for early shifts, sleep end $\left(\mathrm{SE}_{\mathrm{W}}\right)$ is also specific for chronotype. Early chronotypes report a sleep onset $\left(\mathrm{SO}_{\mathrm{W}}\right)$ on morning shifts approximately 1 hour earlier than late types, and later chronotypes also report higher sleep latencies. In contrast to morning shifts, $\mathrm{SO}_{\mathrm{W}}$ after night shifts is almost identical across chronotypes, whereas $\mathrm{SE}_{\mathrm{W}}$ is delayed by up to 1 hour in late compared to early chronotypes.

On evening-shift days, both $\mathrm{SO}_{\mathrm{w}}$ and $\mathrm{SE}_{\mathrm{W}}$ are staggered according to chronotype, similar to the patterns observed on free days following all shifts. That we report no participants used alarm clocks on free days after evening shifts is simply due to the fact that those participants were excluded (see Participants).

\section{Assessing Chronotype Effects}

Social jet lag was significantly influenced by the respective shift $\left(F_{2,428}=62.23, p<0.001\right)$, and effect
Table 2. Average MCTQ ${ }^{\text {Shift }}$ variables on workdays.

\begin{tabular}{|c|c|c|c|c|c|}
\hline & $\mathrm{SO}_{\mathrm{w}}(\mathrm{time})$ & $\mathrm{SE}_{\mathrm{W}}($ time $)$ & Slat $_{\mathrm{W}}(\mathrm{min})$ & $\mathrm{TGU}_{\mathrm{w}}(\mathrm{min})$ & $\mathrm{A}_{\mathrm{W}}$ \\
\hline Morning shift & & & & & \\
\hline Early & $2234 \pm 0054$ & $0434 \pm 0042$ & $15.1 \pm 12.4$ & $6.1 \pm 13$ & 80 \\
\hline Intermediate & $2254 \pm 0051$ & $0438 \pm 0034$ & $19.74 \pm 15.0$ & $5.9 \pm 6.5$ & 92 \\
\hline Late & $2330 \pm 0124$ & $0438 \pm 0024$ & $25.9 \pm 35.4$ & $8.0 \pm 8.6$ & 98.3 \\
\hline Evening shift & & & & & \\
\hline Early & $0025 \pm 0044$ & $0741 \pm 0104$ & $13.9 \pm 13.4$ & $11.2 \pm 14.5$ & 5 \\
\hline Intermediate & $0104 \pm 0048$ & $0829 \pm 0051$ & $13.8 \pm 8.9$ & $13.8 \pm 18.1$ & 17 \\
\hline Late & $0137 \pm 0120$ & $0953 \pm 0106$ & $21.2 \pm 33.6$ & $11.4 \pm 8.9$ & 25 \\
\hline Night shift & & & & & \\
\hline Early & $0734 \pm 0106$ & $1306 \pm 0128$ & $12.7 \pm 19.3$ & $16.6 \pm 23.7$ & 7 \\
\hline Intermediate & $0735 \pm 0043$ & $1321 \pm 0124$ & $13.4 \pm 16.8$ & $14.2 \pm 11.3$ & 11 \\
\hline Late & $0740 \pm 0057$ & $1416 \pm 0129$ & $15.5 \pm 25.8$ & $14.5 \pm 12.1$ & 18.3 \\
\hline
\end{tabular}

$\mathrm{SO}=$ sleep onset; $\mathrm{SE}=$ sleep end $\mathrm{SL}=$ sleep latency; $\mathrm{TGU}=$ time to get up; $\mathrm{A} \%$ = percentage of subjects waking with an alarm clock. The subscript "W" indicates workdays. Mean $\pm \mathrm{SD}$ of the MCTQ ${ }^{\text {Shitt's }} \mathrm{main}$ variables on workdays of the different shifts. According to their $\mathrm{MSF}^{\mathrm{E}}{ }_{\mathrm{sc}}$, the 238 shift-workers were grouped into early $(n=105-115)$, intermediate $(n=60-63)$, and late types $(n=57-60)$. Please take into account that such categorization is arbitrary, given that chronotype is a continuous trait; the distribution (mean, SD, range) of chronotypes in this sample resembles the one observed in day workers (e.g., Roenneberg et al., 2007a). Due to missing data, sample sizes differed slightly between variables.

Table 3. MCTQ $Q^{\text {Shift }}$ variables on free days.

\begin{tabular}{|l|l|l|l|l|c|}
\hline & $\mathbf{S O}_{\mathrm{F}}(\mathrm{time})$ & $\mathrm{SE}_{\mathrm{F}}(\mathrm{time})$ & $\mathrm{SL}_{\mathrm{F}}(\mathrm{min})$ & $\mathrm{TGU}_{\mathrm{F}}(\mathrm{min})$ & $\mathbf{A}_{\mathrm{F}}$ \\
\hline Morning shift & & & & & \\
\hline Early & $2311 \pm 0048$ & $0718 \pm 0128$ & $12.7 \pm 9.2$ & $15.2 \pm 28.6$ & 4 \\
\hline Intermediate & $0010 \pm 0056$ & $0809 \pm 0106$ & $14.9 \pm 9.8$ & $16.8 \pm 31.0$ & 10 \\
\hline Late & $0017 \pm 0125$ & $0944 \pm 0154$ & $17.2 \pm 19.2$ & $15.0 \pm 10.3$ & 2 \\
\hline Evening shift & & & & & \\
\hline Early & $2317 \pm 0045$ & $0743 \pm 0059$ & $12.4 \pm 8.7$ & $10.7 \pm 12.5$ & 0 \\
\hline Intermediate & $0043 \pm 0037$ & $0833 \pm 0046$ & $14.2 \pm 8.9$ & $12.1 \pm 9.9$ & 0 \\
\hline Late & $0216 \pm 0114$ & $1027 \pm 0130$ & $18.4 \pm 31.7$ & $12.8 \pm 8.8$ & 0 \\
\hline Night shift & & & & & \\
\hline Early & $2351 \pm 0151$ & $0750 \pm 0155$ & $22.1 \pm 32.0$ & $15.7 \pm 19.8$ & 6 \\
\hline Intermediate & $0117 \pm 0211$ & $0900 \pm 0119$ & $26.5 \pm 48.0$ & $12.8 \pm 10.4$ & 9 \\
\hline Late & $0237 \pm 0204$ & $1058 \pm 0232$ & $22.9 \pm 36.3$ & $13.3 \pm 11.0$ & 5 \\
\hline
\end{tabular}

The subscript "F" indicates free days. See legend to Table 1 for details. Mean \pm SD of the MCTQ ${ }^{\text {Shift's }}$ main variables on free days subsequent to the different shifts. 


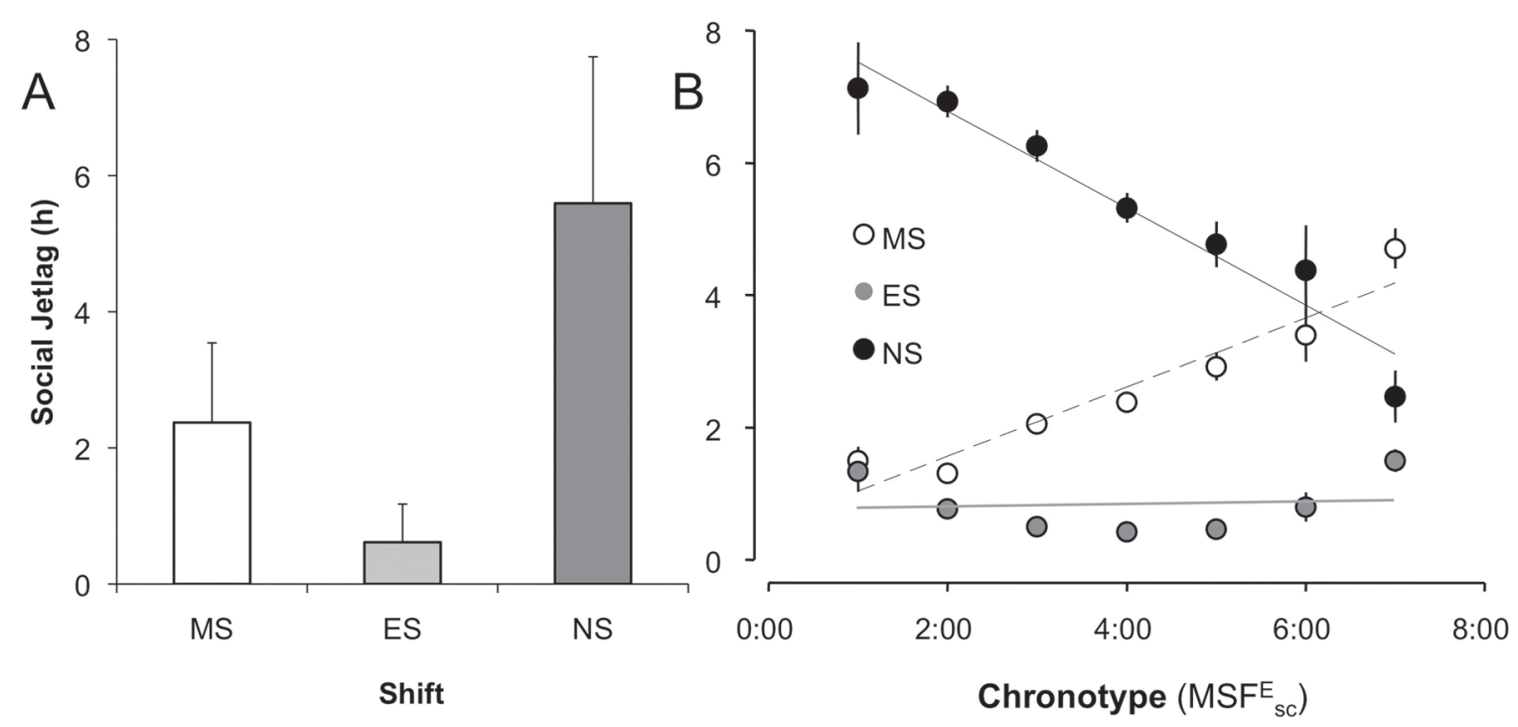

Figure 1. (A) Social jet lag across shifts. Mean \pm SD $(n=230-238)$. (B) Chronotype modulation of social jet lag. Mean \pm SEM. Data are binned in 1-hour intervals. MS = morning shift; ES = evening shift; NS = night shift.
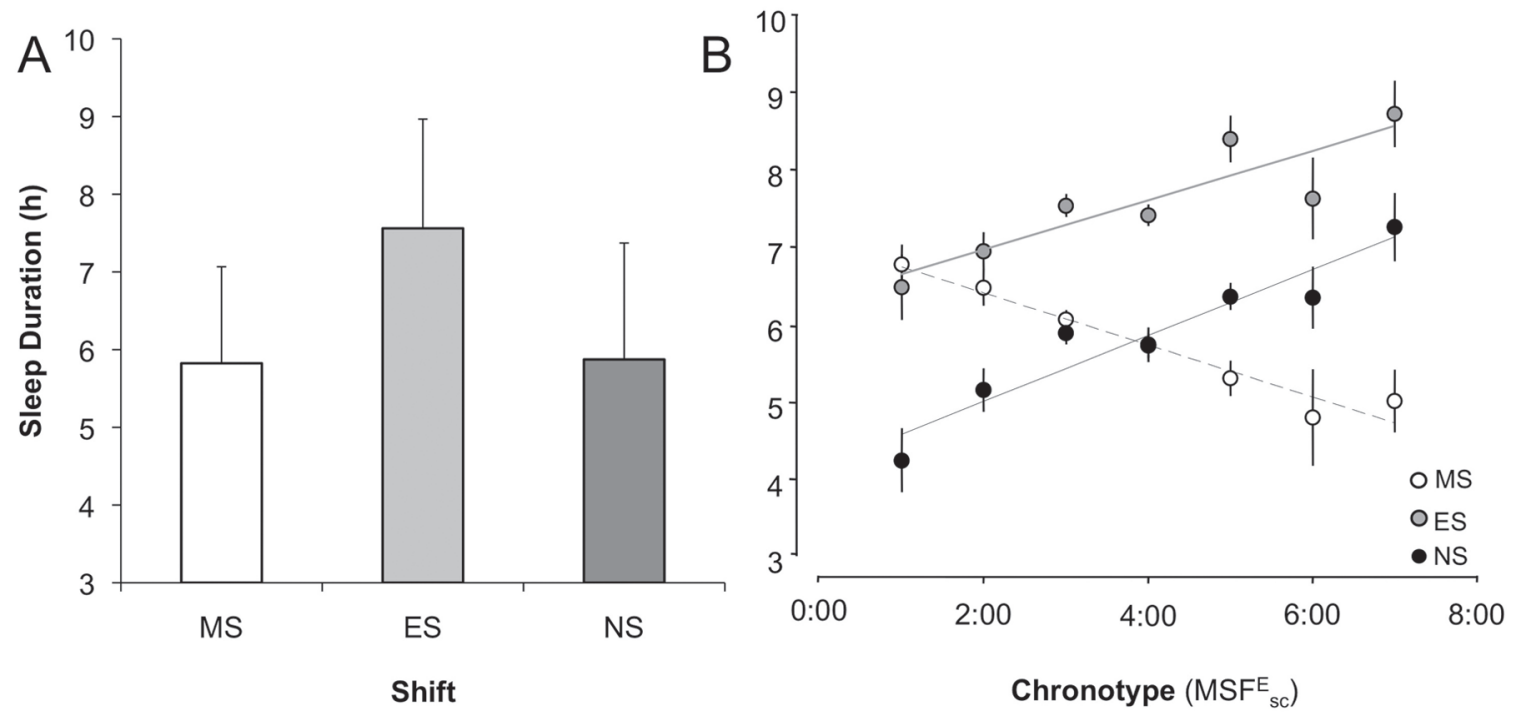

Figure 2. (A) Sleep duration across shifts. Mean \pm SD $(n=231-238)$. (B) Chronotype modulation of sleep duration. Mean \pm SEM. Data are binned in 1-hour intervals. MS = morning shift; $\mathrm{ES}=$ evening shift; $\mathrm{NS}=$ night shift.

accounted for up to $34 \%$ of variance in the data (partial $\eta^{2}=0.34$ ). As shown in Figure $1 B$, social jet lag was highest for earlier chronotypes during night shifts $(r=-0.49, p<0.001)$, while later chronotypes experienced higher social jet lag on morning shifts $(r=0.59, p<0.001)$. Social jet lag on evening shifts appears to be independent of chronotype $(r=-0.01$, $p>0.5)$. The factors age, rotation direction, and speed of rotation did not significantly impact social jet lag, neither as main effects nor in interaction with any other factor (all $p>0.1$ ). Despite chronotype strongly modulating social jet lag in a shift-specific way, it had no main effect on social jet lag.

Sleep duration differed significantly across shifts $\left(F_{2,434}=20.48, p<0.001\right.$, partial $\eta^{2}=0.086$; Fig. 2A $)$. Sleep duration on morning- and night-shift days showed no differences ( $p=1.00$; post hoc pairwise comparisons), but both were significantly different 

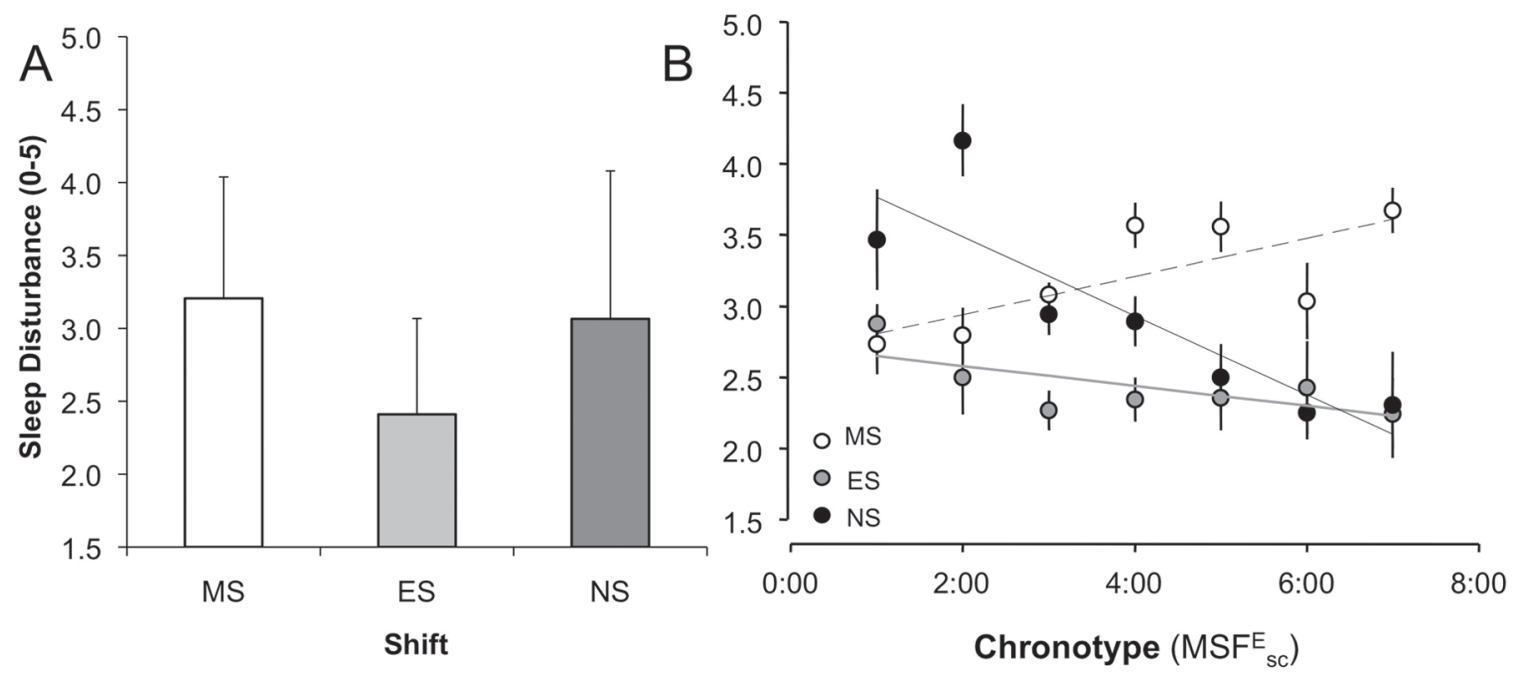

Figure 3. (A) Sleep disturbance across shifts. Mean \pm SD $(n=91-94)$. (B) Chronotype modulation of sleep disturbance. Mean \pm SEM. Data are binned in 1-hour intervals. MS = morning shift; ES = evening shift; $N S=$ night shift.

from sleep duration on evening-shift days $(p<0.001)$. As shown for social jet lag, a highly significant interaction between chronotype and shift emerged for sleep duration $\left(F_{2,434}=61.95, p<0.001\right)$, accounting for $22 \%$ of the variance (partial $\eta^{2}=0.22$ ). On morning-shift days, earlier chronotypes slept longer than later chronotypes $(r=-0.46, p<0.001)$, whereas the opposite was true for night shifts $(r=0.32, p<0.001)$. On evening-shift days, later chronotypes slept slightly longer than earlier ones $(r=0.20, p<0.05$; all controlled for age; Fig. 2B). We also observed a small effect on sleep duration exerted by the interaction between the factors shift and rotation speed (fast v. slow: $F_{2,434}=4.45, p<0.05$, partial $\eta^{2}=0.02$ ). Sleep durations on evening-shift days differed by approximately 40 minutes (mean \pm SE; slow: $7.60 \pm 0.97 \mathrm{~h} \mathrm{v}$. fast: $8.19 \pm 0.26 \mathrm{~h}$ ), whereas sleep duration was comparable on morning- and night-shift days, as indicated by a significant quadratic trend $\left(F_{1,217}=9.87\right.$, $p<0.01)$ for this interaction. Last, the analyses revealed a significant age effect on sleep duration $\left(F_{1,217}=20.38, p<0.001\right.$, partial $\left.\eta^{2}=0.09\right)$; with increasing age, participants slept shorter $(r=-0.16$, $p<0.01)$. Furthermore, backward, rotating shift schedules were associated with longer average sleep duration (main effect [mean $\pm \mathrm{SE}$ ]; forward: $6.23 \pm$ 0.08 h v. backward: $6.71 \pm 0.11$ h; $p<0.01$ ). Note that chronotype per se did not affect sleep duration.

Similar patterns emerged for sleep disturbance (SDis-sample): shift itself influenced the level of sleep disturbance $\left(F_{2,182}=6.15, p<0.01\right)$ but only explained $3 \%$ of the variance (partial $\eta^{2}=0.03$ ). As described for sleep duration, the levels of sleep disturbance on morning- and night-shift days were comparable $(p=$ $0.19)$ but differed from evening-shift days $(p<0.001$; Fig. 3A). The interaction between chronotype and shift explained more of the variation in the sleep disturbance data $\left(F_{2,182}=20.91, p<.001\right.$, partial $\eta^{2}=0.19$; Fig. 3B): on morning-shift days, sleep was worse for later than for earlier chronotypes $(r=0.39, p<0.001)$, while the reverse was true for night shifts $(r=-0.39$, $p<0.001)$. Sleep disturbance on evening-shift days was independent of chronotype $(r=-0.04, p>0.5$; all controlled for age). Age did not have a differential impact dependent on the shift but per se altered the level of sleep disturbance $\left(F_{1,91}=5.77, p<0.05\right)$, accounting for $6 \%$ of the variance in the data (partial $\eta^{2}=0.06$ ). Again, increasing age was related with more disturbed sleep $(r=-0.11, p>0.5)$, but this post hoc test did not reach significance. Again, chronotype per se did not influence sleep disturbance.

For the SDis-sample, we could not examine the impact of rotation direction or speed since all participants worked the same shift schedules, that is, slowly forward rotating.

\section{DISCUSSION}

This study explored whether MCTQ ${ }^{\text {Shift-based }}$ chronotype modulated sleep duration, sleep quality, and social jet lag in a population of workers employed in rotating schedules. Our results show a clear and consistent chronotype modulation of shift-specific 
sleep parameters as well as of social jet lag. An effect of chronotype was only detectable when shifts were analyzed separately, whereas chronotype across all shifts had no effect. On morning-shift days, later chronotypes experienced the highest constraints on sleep, with higher social jet lag, shorter sleep duration, and reduced sleep quality, while early chronotypes showed a similar pattern on night-shift days. Evening shifts (1400 h to $2200 \mathrm{~h}$ ) did not show chronotypespecific modulations, except for sleep duration, with later chronotypes sleeping slightly longer than earlier chronotypes. Work end times around $2200 \mathrm{~h}$ may be late enough to challenge sleep behavior in very early chronotypes: assuming an average sleep duration of 7.5 hours and an $\mathrm{MSF}^{\mathrm{E}}$ of $0200 \mathrm{~h}$, sleep onset at $2215 \mathrm{~h}$ is hardly feasible, given commute times and the time needed to get ready for bed.

In general, our findings support experimental studies showing a decrease in sleep duration and quality depending on the degree of misalignment between the sleep/wake cycle and the circadian clock (Åkerstedt and Gillberg, 1981; Åkerstedt et al., 2007; Dumont et al., 2001; Hennig et al., 1998; Koller et al., 1994; Quera-Salva et al., 1997; Roden et al., 1993; Strogatz et al., 1986). For example, sleep becomes increasingly difficult to maintain the later in the day sleep onset occurs (e.g., early morning hours as is the case after night shifts). This difficulty depends on chronotype: the earlier the chronotype, the harder to sleep into the day. To get sufficient sleep before morning shifts, workers would have to fall asleep early in the evening. Intermediate and especially late chronotypes thereby try to fall asleep during their wake maintenance zone (Strogatz et al., 1987), representing a time span when sleep initiation is most difficult due to a high circadian propensity for alertness. Accordingly, Folkard and Barton (1993) reported that sleep onset on morning-shift days partially depends on circadian factors rather than on social determinants.

Our data analyses did not take into account sociodemographic information, such as marital status or children. It is obvious that plans for novel work schedules should take into account both social and biological factors. Here, we provide a general overview of chronotype effects across different rotating shifts. Previous research indicated rather small effects of sociodemographics on sleep behavior in shift-workers (Folkard and Barton, 1993; Åkerstedt and Torsvall, 1981). Since chronotype is based on "unrestricted sleep timing," theoretically, we do not expect different results when controlling for marital status or children in the household. Yet, future research with larger datasets is needed to elucidate the interactions and effects between social and biological influences, especially regarding the impact of shift-work in individuals who can never sleep without being woken up by children, pets, or other social commitments.

We found a small age effect (shorter and more disturbed sleep with increasing age). Yet, no interaction with specific shifts was observed, unlike in previous studies in which age had a differential effect on morning- and night-shift days, suggesting that older shift-workers had less sleep problems during morning shifts but shortened and more disturbed sleep during night shifts (e.g., Åkerstedt and Torsvall, 1981). However, one main difference between those studies and ours is the analyses and the instrument used to assess chronotype: while Åkerstedt and Torsvall (1981) used the Diurnal Type Scale (Torsvall and Åkerstedt, 1980) and a regression-based analysis approach, we entered chronotype as a continuous covariate in a repeated-measures analysis of variance and used the newly developed MCTQ ${ }^{\text {Shift. By using }}$ the identical instrument for the assessment of sleep duration and chronotype, one may postulate a higher reliability between datasets, especially since $\mathrm{MCTQ}^{\text {Shift }}$ variables were validated against sleep logs and actigraphy, showing an adequate correspondence (Juda et al., 2013). We consistently observe that chronotype plays a significant role interacting with a specific shift, while age shows more general effects. Indeed, it has been suggested that sleep duration and quality decrease with age (Basner et al., 2007; Ohayon et al., 2004). Further longitudinal research is needed to clarify the general relationship between age, chronotype, and sleep, especially in shift-workers. Crosssectional data, however, also show variability in chronotype within older age ranges (Roenneberg et al., 2007a). In our sample, age significantly correlated with chronotype $(r=-0.45)$, but chronotype among the older participants ( $>45$ years) still showed a large variation (0118 $\mathrm{h}$ to $0654 \mathrm{~h}$ ), suggesting that age is not a convenient surrogate for chronotype and vice versa when it comes to understanding the effect of shift-work on sleep.

According to our results, sleep duration in shiftworkers also depends on rotation speed: in fast rotations, evening shifts allowed significantly longer sleep than in slow rotations. Rapid rotating schedules have been proposed to be least disruptive for the circadian system (for review, see Knauth, 1996). The benefits of a faster rotation were only detectable for evening shifts and not for morning and night shifts. However, our results are preliminary since only 32 participants 
worked in fast rotations, and further investigations are needed to show a detailed relationship between chronotype, rotation speed, and direction.

Social jet lag was, in general, highest for night shifts (2200 h to $0600 \mathrm{~h}$ ), which is not surprising in view of the fact that only $0.16 \%$ of the general population would sleep outside of this window even on free days ( $N=93,000$; unpublished data taken from the MCTQ database). However, night shifts are certainly less strenuous for very late chronotypes, as early shifts are for early chronotypes $(6 \%$ of the population wakes up early enough on free days to be at work at around $0600 \mathrm{~h}$; unpublished data taken from the MCTQ database). Early chronotypes suffer from massive social jet lag on night shifts, more than intermediate chronotypes experience in any given shift (day workers experience on average 1 to 2 hours of social jet lag; Roenneberg et al., 2012).

Our findings also have ergonomic implications. Sleepiness and fatigue are considered major risk factors for work injuries and accidents (Berger and Hobbs, 2006; de Pinho et al., 2006; Folkard and Lombardi, 2004; Folkard and Tucker, 2003; Häkkänen and Summala, 2000; Pandi-Perumal et al., 2006; Roth and Ancoli-Israel, 1999), as they have been linked to distortions and impairments in diverse cognitive skills (reasoning abilities, decision making, temporal order judgment, memory, learning, vigilance, and motor skills; Babkoff et al., 2005; Bratzke et al., 2009; Jasper et al., 2009a; Jasper et al., 2009b; Lal and Craig, 2002; Rogers et al., 2004; Steinborn et al., 2010; Van Dongen and Dinges, 2003). Recently, we reported significantly slower reaction times during morning shifts, as compared to night shifts, in a sample of late chronotypes. We also found that chronotype-specific sleep deprivation patterns, as described above, impair performance (Vetter et al., 2012). Besides its impact on cognition and perception, sleep deprivation has also been shown to decrease immune function (Irwin et al., 2006; Lange et al., 2003; Spiegel et al., 2002; Vgontzas et al., 2004), offering a partial explanation for the increased health problems of shift-workers.

The fact that we did not observe a main effect of chronotype on social jet lag, sleep duration, and sleep disturbance is highly relevant because it could explain why previous studies, looking at overall tolerance, failed to find chronotype differences in shiftwork tolerance concerning sleep disturbance, fatigue, mood, and health (e.g., Breithaupt et al., 1978; Costa et al., 1989; Härmä, 1995; Kaliterna et al., 1995; Kaliterna et al., 1993; Tamagawa et al., 2007). Folkard and Hunt (2000) already suggested that chronotype effects may only be observed when examining the shifts separately. Thus, shift-work research will certainly gain more conclusive insights when taking chronotype into account (Kantermann et al., 2010) but also explores shift-specific behaviors. To account for chronotype effects in future research, we suggest computing weighted averages that take into account the exposure of a given chronotype to a certain shift. Also, to compare shift schedules and predict their effect for certain chronotypes, absolute social jet lag may be a useful variable (see supplementary online material of Juda et al., 2013): by using a weighted average, one may track chronotype-specific shiftwork exposure across schedules and time.

Taken together, our results indicate that neither sleep duration, nor sleep quality, nor social jet lag depend on chronotype per se but that chronotype can only account for interindividual variability within the context of work schedules. They also indicate that being an extreme early or late chronotype is not necessarily a sleep disturbance: when individuals are given the chance to sleep within their circadian sleep window, at least sleep duration appears adequate. Sleep of extreme chronotypes is chronically challenged in day workers, with late chronotypes having to get up long before their biological sleep end on every workday and early chronotypes generally staying up too late, tagging along with the majority of late types in the population. Although shift-work is a risk factor for health, it does provide temporal niches for different chronotypes, enabling them to sleep according to their circadian timing despite having to go to work. Thus, the need for shift-work in our society may even hold an opportunity (except for the nocturnal "graveyard shifts"). Our results indicate that intelligently devised shift schedules (i.e., considering chronotype and social needs and excluding work during $0300 \mathrm{~h}$ and $0500 \mathrm{~h}$ ) may constitute an extreme form of work flexibility that allows all chronotypes to get a good night's sleep even on workdays.

\section{ACKNOWLEDGMENTS}

This research was supported by CLOCKWORK Kolleg (funded by Gottlieb Daimler und Karl Benz-Stiftung), Siemens AG, Volkswagen AG, and ArcelorMittal SA. The authors thank the numerous people involved in organizing and implementing the studies, in particular Dr. Angela Guth (Volkswagen AG), Wolfgang Kloke, Wolfgang Eichinger, Dr. Friederike Dunkel-Benz (Siemens AG), and Dr. Marc Jacoby (ArcelorMittal SA). Above all, they are grateful to the many volunteer shift-workers. 


\section{CONFLICT OF INTEREST STATEMENT}

The author(s) declared no potential conflicts of interest with respect to the research, authorship, and/or publication of this article.

\section{REFERENCES}

Åkerstedt T (1983) A questionnaire study of sleep/wake disturbances and irregular work hours. Sleep Res 12:358.

Åkerstedt T (1998) Shift work and disturbed sleep/wakefulness. Sleep Med Rev 2:117-128.

Åkerstedt T (2003) Shift work and disturbed sleep/wakefulness. Occup Med 53:89-94.

Akerstedt T (1995) Work hours and sleepiness. Neurophysiol Clin 25:367-375.

Åkerstedt T and Gillberg M (1981) The circadian variation of experimentally displaced sleep. Sleep 4:159-169.

Åkerstedt T, Kecklund G, and Gillberg M (2007) Sleep and sleepiness in relation to stress and displaced work hours. Physiol Behav 92:250-255.

Åkerstedt T and Torsvall L (1981) Shift work: shift-dependent well-being and individual differences. Ergonomics 24(4):265-273.

Babkoff H, Zukerman GIL, Fostick L, and Ben-Artzi E (2005) Effect of the diurnal rhythm and $24 \mathrm{~h}$ of sleep deprivation on dichotic temporal order judgment. J Sleep Res 14:7-15.

Barton J, Spelten E, Totterdell P, Smith L, Folkard S, and Costa G (1995) The Standard Shiftwork Index: a battery of questionnaires for assessing shiftwork-related problems. Work Stress 9:4-30.

Basner M, Fomberstein KM, Razavi FM, Banks S, William JH, Rosa RR, and Dinges DF (2007) American Time Use Survey: sleep time and its relationship to waking activities. Sleep 30(9):1085-1095.

Berger A and Hobbs B (2006) Impact of shift work on the health and safety of nurses and patients. Clin J Oncol Nurs 10:465-471.

Bratzke D, Rolke B, Steinborn MB, and Ulrich R (2009) The effect of $40 \mathrm{~h}$ constant wakefulness on task-switching efficiency. J Sleep Res 18:167-172.

Breithaupt H, Hildebrandt G, Dhre D, Josch R, Sieber U, and Werner M (1978) Tolerance to shift of sleep, as related to the individual's circadian phase position. Ergonomics 21:767-774.

Burgess HJ and Eastman CI (2005) The dim light melatonin onset following fixed and free sleep schedules. J Sleep Res 14:229-237.

Burgess HJ, Savic N, Sletten T, Roach G, Gilbert SS, and Dawson D (2003) The relationship between dim light melatonin onset and sleep on a regular schedule in young healthy adults. Behav Sleep Med 1(2):102-114.

Carskadon MA and Dement WC (1981) Cumulative effects of sleep restriction on daytime sleepiness. Psychophysiology 18:107-113.

Carskadon MA and Dement WC (1987) Daytime sleepiness: quantification of a behavioral state. Neurosci Biobehav Rev 11:307-317.
Costa G, Lievore F, Casaletti G, Gaffuri E, and Folkard S (1989) Circadian characteristics influencing interindividual differences in tolerance and adjustment to shiftwork. Ergonomics 32:373-385.

Czeisler CA, Allan JS, Strogatz SH, Ronda JM, Sánchez R, Ríos CD, Freitag WO, Richardson GS, and Kronauer RE (1986) Bright light resets the human circadian pacemaker independent of the timing of the sleep-wake cycle. Science 233:667-671.

Czeisler CA, Johnson MP, Duffy JF, Brown EN, Ronda JM, and Kronauer RE (1990) Exposure to bright light and darkness to treat physiologic maladaptation to night work. N Engl J Med 322:1253-1259.

de Pinho RSN, da Silva-Júnior FP, Bastos JPC, Maia WS, de Mello MT, de Bruin VMS, and de Bruin PFC (2006) Hypersomnolence and accidents in truck drivers: a cross-sectional study. Chronobiol Int 23:963-971.

Dumont M, Benhaberou-Brun D, and Paquet J (2001) Profile of 24-h light exposure and circadian phase of melatonin secretion in night workers. J Biol Rhythms 16:502-511.

Folkard S (2008) Do permanent night workers show circadian adjustment? A review based on the endogenous melatonin rhythm. Chronobiol Int 25:215-224.

Folkard S and Barton T (1993) Does the 'forbidden zone' for sleep onset influence morning shift sleep duration? Ergonomics 36(1-3):85-91.

Folkard S and Hunt LJ (2000) Morningness-eveningness and long-term shift work tolerance. In Shift Work in the 21st Century (Arbeitswissenschaft in der Betrieblichen Praxis), Hornberger S, Knauth P, Costa G, and Folkard S, eds, vol 17, pp 311-316. Frankfurt: Peter Lang.

Folkard S and Lombardi DA (2004) Toward a "risk index" to assess work schedules. Chronobiol Int 21:1063-1072.

Folkard S, Minors DS, and Waterhouse JM (1985) Chronobiology and shift work: current issues and trends. Chronobiologia 12:31-54.

Folkard S and Tucker P (2003) Shift work, safety and productivity. Occup Med 53:95-101.

Greenwood KM (1992) Long-term stability and psychometric properties of the Composite Scale of Morningess. Ergonomics 37(2):377-383.

Häkkänen H and Summala H (2000) Sleepiness at work among commercial truck drivers. Sleep 23:49-57.

Härmä M (1993) Individual differences in tolerance to shiftwork: a review. Ergonomics 36(1-3):101-109.

Härmä M (1995) Sleepiness and shiftwork: individual differences. J Sleep Res 4:57-61.

Härmä M, Tenkanen L, Sjöblom T, Alikoski T, and Heinsalmi P (1998) Combined effects of shift work and life-style on the prevalence of insomnia, sleep deprivation and daytime sleepiness. Scand J Work Environ Health 24:300-307.

Hennig J, Kieferdorf P, Moritz C, Huwe S, and Netter P (1998) Changes in cortisol secretion during shiftwork: implications for tolerance to shiftwork? Ergonomics 41:610-621.

Horne JA and Østberg O (1976) A self-assessment questionnaire to determine morningness-eveningness in human circadian rhythms. Int J Chronobiol 4:97-110.

Irwin MR, Wang M, Campomayor CO, Collado-Hidalgo A, and Cole S (2006) Sleep deprivation and activation of morning levels of cellular and genomic markers of inflammation. Arch Int Med 166:1756-1762. 
Jasper I, Häußler A, Baur B, Marquardt C, and Hermsdörfer $\mathrm{J}$ (2009a) Circadian variations in the kinematics of handwriting and grip strength. Chronobiol Int 26:576-594.

Jasper I, Häußler A, Marquardt C, and Hermsdörfer J (2009b) Circadian rhythm in handwriting. J Sleep Res 18:264-271.

Juda M, Vetter C, and Roenneberg T (2013) The Munich ChronoTypeQuestionnaire for shift-workers (MCTQ $\left.{ }^{\text {Shift }}\right)$. J Biol Rhythms 28:130-140.

Kaliterna L, Vidaček S, Prizmić Z, and RadoševićVidaček B (1995) Is tolerance to shiftwork predictable from individual difference measures? Work Stress 9:140-147.

Kaliterna L, Vidaček S, Radošević-Vidaček B, and Prizmić Z (1993) The reliability and stability of various individual difference and tolerance to shiftwork measures. Ergonomics 36:183-189.

Kantermann T, Juda M, Merrow M, and Roenneberg T (2007) The human circadian clock's seasonal adjustment is disrupted by daylight saving time. Curr Biol 17:1996-2000.

Kantermann T, Juda M, Vetter C, and Roenneberg T (2010) Shift-work research: where do we stand, where should we go? Sleep Biol Rhythms 8:95-105.

Knauth P (1996) Designing better shift systems. Appl Ergon 27(1):39-44.

Koller M, Härma M, Laitinen JT, Kundi M, Piegler B, and Haider M (1994) Different patterns of light exposure in relation to melatonin and cortisol rhythms and sleep of night workers. J Pineal Res 16:127-135.

Kuehnle T (2006) Quantitative Analysis of Human Chronotype. Doctoral dissertation. Munich: Ludwig Maximilian University of Munich.

Lal SKL and Craig A (2002) Driver fatigue: electroencephalography and psychological assessment. Psychophysiology 39:313-321.

Lange T, Perras B, Fehm HL, and Born J (2003) Sleep enhances the human antibody response to hepatitis A vaccination. Psychosom Med 65:831-835.

Martin SK and Eastman CI (2002) Sleep logs of young adults with self-selected sleep times predict the dim light melatonin onset. Chronobiol Int 19:695-707.

Ohayon MM, Carskadon MA, Guilleminault C, and Vitiello MV (2004) Meta-analysis of quantitative sleep parameters from childhoof to old age in healthy individuals: developing normative sleep values across the human life span. Sleep 27(7):1255-1273.

Pandi-Perumal SR, Verster JC, Kayumov L, Lowe AD, Santana MG, Pires ML, Tufik S, and Mello MT (2006) Sleep disorders, sleepiness and traffic safety: a public health menace. Braz J Med Biol Res 39:863-871.

Quera-Salva MA, Guilleminault C, Claustrat B, Defrance R, Gajdos P, McCann CC, and De Lattre J (1997) Rapid shift in peak melatonin secretion associated with improved performance in short shift work schedule. Sleep 20:1145-1150.

Roden M, Koller M, Pirich K, Vierhapper H, and Waldhauser F (1993) The circadian melatonin and cortisol secretion pattern in permanent night shift workers. Am J Physiol 265:R261-R267.

Roenneberg T (2012) What is chronotype? Sleep Biol Rhythms 10:75-76.
Roenneberg T, Allebrandt Karla V, Merrow M, and Vetter C (2012) Social jetlag and obesity. Curr Biol 22:939-943.

Roenneberg T, Kuehnle T, Juda M, Kantermann T, Allebrandt K, Gordijn M, and Merrow M (2007a) Epidemiology of the human circadian clock. Sleep Med Rev 11:429-438.

Roenneberg T, Kumar CJ, and Merrow M (2007b) The human circadian clock entrains to sun time. Curr Biol 17(2):R44.

Roenneberg T, Wirz-Justice A, and Merrow M (2003) Life between clocks: daily temporal patterns of human chronotypes. J Biol Rhythms 18:80-90.

Rogers AE, Hwang W-T, and Scott LD (2004) The effects of work breaks on staff nurse performance. J Nurs Adm 34:512-519.

Roth T and Ancoli-Israel S (1999) Daytime consequences and correlates of insomnia in the United States: results of the 1991 National Sleep Foundation Survey II. Sleep 22(Suppl 2):S354-S358.

Seo Y-J, Matsumoto K, Park Y-M, Shinkoda H, and Noh T-J (2000) The relationship between sleep and shift system, age and chronotype in shift workers. Biol Rhythms Res 31(5):559-579.

Spiegel K, Sheridan JF, and Van Cauter E (2002) Effect of sleep deprivation on response to immunization. JAMA 288:1471-1472.

Steinborn MB, Bratzke D, Rolke B, Gordijn MCM, Beersma DGM, and Ulrich R (2010) The effect of 40 hours of constant wakefulness on number comparison performance. Chronobiol Int 27:807-825.

Strogatz SH, Kronauer RE, and Czeisler CA (1987) Circadian pacemaker interferes with sleep onset at specific times each day: role in insomnia. Am J Physiol 253:R172-R178.

Strogatz SH, Kronauer RE, and Czeisler CA (1986) Circadian regulation dominates homeostatic control of sleep length and prior wake length in humans. Sleep 9:353-364.

Tamagawa R, Lobb B, and Booth R (2007) Tolerance of shift work. Appl Ergon 38:635-642.

Torsvall L and Akerstedt T (1980) A diurnal type scale: construction, consistency and validation in shift work. Scand J Work Environ Health 6:283-290.

Van Dongen HPA and Dinges DF (2003) Investigating the interaction between the homeostatic and circadian processes of sleep-wake regulation for the prediction of waking neurobehavioural performance. J Sleep Res 12:181-187.

Vetter C, Juda M, and Roenneberg T (2012) The influence of internal time, time awake, and sleep duration on cognitive performance in shiftworkers. Chronobiol Int 29:1127-1138.

Vgontzas AN, Zoumakis E, Bixler EO, Lin H-M, Follett H, Kales A, and Chrousos GP (2004) Adverse effects of modest sleep restriction on sleepiness, performance, and inflammatory cytokines. J Clin Endocrinol Metab 89:2119-2126.

Wittmann M, Dinich J, Merrow M, and Roenneberg T (2006) Social jetlag: misalignment of biological and social time. Chronobiol Int 23:497-509. 